Network Working Group

Request for Comments: 3615

Category: Informational
J. Gustin

A. Goyens SWIFT

September 2003

\title{
A Uniform Resource Name (URN) Namespace for SWIFT Financial Messaging
}

Status of this Memo

This memo provides information for the Internet community. It does not specify an Internet standard of any kind. Distribution of this memo is unlimited.

Copyright Notice

Copyright (C) The Internet Society (2003). All Rights Reserved.

Abstract

This document describes a Uniform Resource Name (URN) namespace that is managed by SWIFT for usage within messages standardized by SWIFT.

1. Introduction

SWIFT is an industry-owned cooperative supplying secure, standardised messaging services and interface software to over 7,500 financial institutions in 199 countries. The SWIFT community includes banks, broker/dealers and investment managers, as well as their market infrastructures in payments, securities, treasury and trade.

The goal of this namespace is to ensure the stability and uniqueness of the names of various items that are used within the messages exchanged between financial institutions. SWIFT is one of the principal standardization bodies for financial messages and services. This standardization process identifies the structure and meaning of messages exchanged for various financial services offered by financial institutions. It is essential that names of items (such as the XML schema describing the message itself) can be used to identify the resource even years after the message has been exchanged.

The same resource may exist in multiple physical locations, and thus multiple URL's, but only a single URN. 


\section{Specification Template}

Namespace ID:

"swift"

Registration Information:

Version 1

Date: 2001-08-01

Declared registrant of the namespace:

SWIFT S.C.r.l.

Avenue Adele 1

B-1310 La Hulpe

Belgium

Declaration of syntactic structures:

The structure of the Namespace Specific String is a flat space <URN chars> [1] which have no knowable structure outside of the context of the SWIFT community internal resolver. Future changes to the assignment methods may allow others to assign sub-spaces of the flat namespace but again, this knowledge is only valid internally and should never be inferred or relied upon externally.

Relevant ancillary Documentation:

None

Identifier uniqueness considerations:

Identifiers are assigned by SWIFT URN Registration that guarantees uniqueness. This is simply achieved by keeping track of already assigned names and comparing all new proposed names to the database ones. If the name already exists a new one has to be proposed.

Identifiers persistence considerations:

The assignment process guarantees that names are not reassigned. In any case SWIFT URNs are guaranteed to remain valid for 15 years. 
Process of identifiers assignment:

Names are granted via SWIFT proprietary registration procedures.

Process for identifier resolution:

SWIFT URNs are resolved via URN resolvers run under SWIFT responsibility.

Rules for lexical equivalence:

No special consideration.

Conformance with URN syntax:

No special consideration.

Validation mechanism:

None specified.

Scope :

This namespace is reserved to the global financial community.

3. Examples

The following examples are not guaranteed to be real. They are listed for pedagogical reasons only.

urn:swift:xsd:epp\$mi.i-2.0

urn:swift: type: fin\$103

4. Security Considerations

Since the URNs in this namespace are opaque there are no additional security considerations other than those normally associated with the use and resolution of URNs in general.

It is noted however that attempting to resolve a SWIFT URN through a resolver other than the one provided by SWIFT is error prone. In any case, it is not considered authoritative.

5. IANA Considerations

The IANA has registered formal URN namespace 15, to SWIFT within the IANA registry of URN NIDs. 
6. Normative References

[1] Moats, R., "URN Syntax", RFC 2141, May 1997.

[2] Daigle, L., van Gulik, D., Iannella, R. and P. Faltstrom, "Uniform Resource Name (URN) Namespace Definition Mechanisms", BCP 66, RFC 3406, October 2002 .

7. Authors' Addresses

Jean-Marc Gustin

SWIFT s.c.r.l.

Avenue Adele, 1

B1310 La Hulpe

Belgium

EMail: jean-marc.gustineswift.com

Andre Goyens

SWIFT S.C.r.l.

Avenue Adele, 1

B1310 La Hulpe

Belgium

EMail: andre.goyenseswift.com

URI : http://www.swift.com 
8. Full Copyright statement

Copyright (C) The Internet Society (2003). All Rights Reserved.

This document and translations of it may be copied and furnished to others, and derivative works that comment on or otherwise explain it or assist in its implementation may be prepared, copied, published and distributed, in whole or in part, without restriction of any kind, provided that the above copyright notice and this paragraph are included on all such copies and derivative works. However, this document itself may not be modified in any way, such as by removing the copyright notice or references to the Internet society or other Internet organizations, except as needed for the purpose of developing Internet standards in which case the procedures for copyrights defined in the Internet Standards process must be followed, or as required to translate it into languages other than English.

The limited permissions granted above are perpetual and will not be revoked by the Internet society or its successors or assignees.

This document and the information contained herein is provided on an "AS IS" basis and THE INTERNET SOCIETY AND THE INTERNET ENGINEERING TASK FORCE DISCLAIMS ALL WARRANTIES, EXPRESS OR IMPLIED, INCLUDING BUT NOT LIMITED TO ANY WARRANTY THAT THE USE OF THE INFORMATION HEREIN WILL NOT INFRINGE ANY RIGHTS OR ANY IMPLIED WARRANTIES OF MERCHANTABILITY OR FITNESS FOR A PARTICULAR PURPOSE.

Acknowledgement

Funding for the RFC Editor function is currently provided by the Internet society. 